\section{Mononukleäre Zellen}

H. Baum

Institut für Laboratoriumsmedizin, Mikrobiologie und Blutdepot, Regionale Kliniken Holding RKH GmbH, Ludwigsburg, Deutschland

Englischer Begriff mononucleated cell

Definition Zelle mit einem oder einem einfachen Zellkern.
Beschreibung Unter dem Begriff „mononukleäre Zellen“ werden in der Hämatologie all die Zellen zusammengefasst, die nur einen, meist runden bis ovalen Zellkern haben. Dieser Gruppe von Zellen werden die polynukleären Zellen ( $\triangleright$ Polynukleäre Zellen) mit segmentiertem oder stabförmigem Kern, also neutrophile, eosinophile und basophile Granulozyten, gegenübergestellt.

\section{Literatur}

Begemann H, Begemann M (1997) Praktische Hämatologie, 10. Aufl. Georg Thieme Verlag, Stuttgart, S 117-118 